occurs always, I think, at $F$, the cross-section of the bar being proportionately more reduced than the load.

Alex. B. W. Kennedy

University College, March 23

\section{The Colours of Arctic Animals}

THE white colour of Arctic mammals and birds has hitherto been generally ascribed by evolutionists to protective resemblance, the adaptation to a snow-covered country being attributed to the preservation of individuals which by assimilating to their environment in colour, either escaped detection by their foes, or, on the other hand, were by this means enabled to secure their prey more advantageously. Although a certain weight may, in the case of some species, be fairly given to these organic factors, it always appeared to me that this explanation was not in itself sufficient, in face of the consideration that many of the species so coloured could hardly be said to require such protection on account of persecution, or to derive any obvious advantage therefrom for predatory purposes. A more satisfactory explanation seemed to be that the mode of coloration in question had, at any rate in the first instance, been brought about by natural selection through physical rather than through organic agencies. It is well known that white, as the worst absorber, is also the worst radiator of all forms of radiant energy, so that warm-blooded creatures thus clad would be better enabled to withstand the severity of an Arctic climatethe loss of heat by radiation might, in fact, be expected to be less rapid than if the hairs or feathers were of a darker colour. According to a paper recently published by Lord Walsingham, ${ }^{2}$ it seems that this view was entertained as far back as 1846 by Craven, ${ }^{3}$ the only addition to the theory required by modern evolution being that we must regard the white covering as having been acquired by the ordinary Darwinian process of the survival of the fittest, i.e. by the climatic selection of those individuals best fitted to withstand the extremely low temperatures of their habitat.

It is perfectly familiar to zoologists that most animals occasionally give rise to white varieties, so that the basic variations necessary for the establishment of the required modification in the colour of the hair and feathers would not have been wanting during the gradual approach of the Glacial Epoch. It may be conjectured whether white may not have been the prevailing colour among all warm-blooded animals during this period, with the exception, perhaps, of those species in which the severity of the climate may have been met by an equally effective thickening of the fur. Certain species which, like the stoat and ptarmigan, become white during winter, may, from this point of view, be regarded as reverting seasonally to the mode of coloration which in their ancestors was normal during the Glacial Epoch, the reversion being in these cases brought about by the same influences which formerly fixed white as the most advantageous form of covering. In accordance with this view, it is sometimes asserted that the stoat docs not commonly turn white during winter in the south of England, excepting in very severe seasons. ${ }^{4}$ Further observations on this point are much needed.

In striking contrast to the white covering of Arctic and Alpine mammals and birds, it has been found that there is a quite opposite tendency for the insects to become darker and more suffused, this melanism being especially noticeable among many of the Lepidoptera. Although numerous speculations as to the cause of this phenomenon have from time to time been advanced, it is in the paper by Lord Walsingham above referred to that what appears to be a true cause has for the first time been suggested. The author has, in fact, most ingenionsly extended the very argument which had been adduced to account for the white colour of the mammals and birds to explain the quite opposite melanism of the insects. According to the present view the the melanic tendency of northern Lepidoptera must be ascribed to the natural selection of the darker forms owing to the advantage which these would possess in being able to absorb more of the solar radiation than their lighter congeners. The same action must be regarded as here bringing about opposite effects : in the case of warm-blooded animals the loss of heat by radiation is retarded by the white covering, whilst in insects, which

I Trans. Essex Field Club, vol. i. Proc., March 20, r880, p. vi. 2 "On some probable causes of a tendency to melanic variation in Lepidoptera of high latitudes;" the Annual Presidential Address to the Yorkshire Naturalists' Union, Doncaster, March $3,1885$.

3 "Recreations in Shooting," p. ror.
4 R. M. Christy in Trans. Essex Field Club, vol, i. p. 67 develop but little heat by respiration, it is of the utmost importance to utilise as much as possible of the solar energy. This will be seen to be all the more necessary when it is considered that, under Arctic conditions, the solar rays have but little power, and that the pairing of the insects has to be effected with great rapidity. In order to test these views experimentally, the author exposed numerous species of Lepidoptera of various colours to the sun's rays on a surface of snow, and observed the rate at which the insects sank beneath the surface. As might have been anticipated, the darker insects, like Tantgra charophyllata, sank more rapidly than white moths like Acidalia immutata, which made but little impression on the snow.

The questions raised by these suggestions and observations certainly appear to be well worthy of consideration when dis. cussing the subject of animal coloration. Thus the explanstion of the melanism of Arctic insects now advanced may perhaps, when more fully elaborated, throw further light upon the theory of seasonal dimorphism first proposed by Weismann. ${ }^{1}$ If, in accordance with the views of this author, we regard the present winter forms of these seasonally dimorphic Lepidoptera as the ancestral Glacial types, it becomes clear why in such white species as Pieris napi, the parent Glacial form Bryonice should be the darker. In the case of Araschnia levana the theory does not at first sight apply, inasmuch as the winter form is lighter than the summer generation (Prorsa); here, however, both forms are coloured, and there would be but little difference in their relative heat-absorbing powers. The same remark may apply in the case of our own seasonally dimorphic species of Selenia and Ephyra.

R. Meldgla

\section{An Error in Ganot's "Physics"}

In your issue of February 19 (p. 361), E. Douglas Archibald calls attention to a typical error in Ganot's "Physics," Ioth edition, p. 325, and assumed that it had run through the ten editions. If he had taken the pains to look back to previous editions the formula would have appeared right, viz. :-

$$
P=\frac{0.31}{(I+\alpha t) 760} \frac{V\left(H-\frac{3}{8} F E\right)}{\text { I }}
$$

In going over the text of earlier issues of the book some minor errors are discoverable, but do not detract materially from the value of the same to the careful student

Mountainville, Orange Co., New York, March 4

FRANK E EMERY, ist Asst. Sci. Dent.

WiTH reference to the letter of Mr. Frank E. Emery on mine, calling attention to the typical error in Ganot's "Physics," I beg to say that though in some of the earlier editions the error may not exist, it occurs in the 5 th and roth, both of which are in my possession. The inference is very strong that if it occurs in these two it occurs in the editions intervening, and thus in HALF of the editions published. The first five editions are now getting out of date, so it is not of much value to people if the error does not exist in them.

I would also observe that if Mr. Emery takes the pains of reading my letter over again he will notice it was explicitly stated to be for the benefit of the large class of students who are not careful.

My purpose was in no way to run down Ganot, but to warn people of a pitfall in it.

Tunbridge Wells, March 23

\section{Exceptional Whiteness in Tropical Man}

SingULARLY enough, being encamped in the same place as that from which the paper on "The Blackness of Tropical Man" was written to NATURE some months ago, the converse, a case of the whiteness of this class of man, presented itself unexpectedly. While entering, to-day, the native village of Jeykondashulapurm, that had sunk to nothing from having been the capital of a native dynasty in the south of India, and situated about lat $11^{\circ} \mathrm{N}$. and long. $78^{\circ} \mathrm{E}$., the writer observed an apparently white woman sitting on a doorstep by the side of the road, with flaxen-coloured

I I may take the present opportunity of pointing ont to those who possess the English edition of the "Studies in the Theory of Descent" that an error inadvertently occurs in the numbering of the figures in Plate I. Figs. 2, 3, inadvertently occurs in the numbering of the figures in Plate I. Figs. 2,3 , indebted to Mr. E. B. Poulton for kindly calling my attention to this transposition. 